Relationship between bone strength and dual-energy X-ray absorptiometry measurements in pigs

Nielsen, Dorte Hald; McEvoy, Fintan; Madsen, M.T.; Jensen, J.B.; Svalastoga, Eiliv Lars

Published in:

Journal of Animal Science

DOI:

10.2527/jas.2006-025

Publication date:

2007

Document version

Publisher's PDF, also known as Version of record

Citation for published version (APA):

Nielsen, D. H., McEvoy, F., Madsen, M. T., Jensen, J. B., \& Svalastoga, E. L. (2007). Relationship between bone strength and dual-energy X-ray absorptiometry measurements in pigs. Journal of Animal Science, 85(3), 667-672. https://doi.org/10.2527/jas.2006-025 


\title{
Relationship between bone strength and dual-energy X-ray absorptiometry measurements in pigs
}

\author{
D. H. Nielsen, ${ }^{* 1}$ F. J. McEvoy, ${ }^{*}$ M. T. Madsen, $†$ J. B. Jensen, $‡$ and E. Svalastoga
}

*The Royal Veterinary and Agricultural University, Dyrlaegevej 32, DK-1870 Frederiksberg C, Denmark; $\dagger$ The National Committee for Pig Production, Axeltorv 3, DK-1609 Copenhagen, Denmark; and $\$$ Hvidovre University Hospital, Kettegaard Alle 30, DK-2650 Hvidovre, Denmark

\begin{abstract}
Computed tomography and a 3-point bending test were performed on the metacarpal bones of adult production pigs to test the hypothesis that bone strength is strongly correlated with areal bone mineral density (BMD) in this population. The aim of the study was to subject material from adult production pigs grouped by BMD to 3-point bending, to test this hypothesis and determine any correlations. In all, 168 individual computed tomography scans and mechanical tests were performed on the collected material. For evaluation purposes, the material was divided into the categories low, medium, and high $\mathrm{BMD}(<1,1$ to 1.4 , and $>1.4$ $\mathrm{g} / \mathrm{cm}^{2}$, respectively). The results showed a difference in
\end{abstract}

the maximum load, in the stress at maximum load, and stiffness among each BMD group $(P<0.001)$ and in elastic modulus between the low BMD group and the 2 other groups $(P<0.001)$. A correlation between both intrinsic and extrinsic measures of bone strength and BMD was thus demonstrated. The projected change in each of the variables reported, for a $0.1 \mathrm{~g} / \mathrm{cm}^{2}$ alteration in BMD (within the BMD range evaluated in this study), is as follows: maximum load, $708 \mathrm{~N}$; stress at maximum load, $50 \mathrm{~N} / \mathrm{mm}^{2}$; stiffness, $391.6 \mathrm{~N} / \mathrm{mm}$; and elastic modulus, $108 \mathrm{~N} / \mathrm{mm}^{2}(P<0.001)$. The results confirm the relationship between BMD and bone strength and indicate that BMD screening can be used in fracture risk assessments in production pigs.

Key words: bone mineral density, pig, 3-point bending test

(c)2007 American Society of Animal Science. All rights reserved.

J. Anim. Sci. 2007. 85:667-672

doi: 10.2527/jas.2006-025

\section{INTRODUCTION}

A balance in pig production between the pressure to increase stocking rates and the environmental effect of the associated slurry is required. The pig industry is careful to minimize pollutants in slurry by decreasing the mineral content in feed. The potential animal welfare effect of this, particularly the possibility of predisposing pigs to bone fractures, is clear. An increase in fractures detected at slaughter has been reported (Christensen and Wachman, 2001). To meet the concern over fracture risk in pigs fed low mineral diets, a practical, objective method is needed to measure bone strength. Such measurements can be used in screening procedures to detect important changes in bone strength or to address public concern.

Dual-energy X-ray absorptiometry (DXA) results, obtained using a protocol suitable for mass screening in the pig, are highly reproducible and give an accurate estimate of bone mineral content and bone mineral den-

${ }^{1}$ Corresponding author: dhn@kvl.dk

Received January 12, 2006.

Accepted October 29, 2006. sity (BMD; Nielsen et al., 2004). Other studies examining the relationship between BMD and bone strength are limited to growing pigs (Koo et al., 2001; Van der Meulen et al., 2001) and other animal species and have shown a correlation between these variables (Alho et al., 1988, Iida-Klein et al., 2006).

The relationship between BMD and fracture risk is complex (Alho et al., 1988; Faulkner, 2000; Wachter et al., 2002). The structural arrangement of the whole bone has an important effect on its function (Stenstrom et al., 2000; Van der Meulen et al., 2001). Given the importance of structure, a correlation between BMD alone and bone strength cannot be assumed.

This study addressed the question of whether BMD values, acquired following the previously reported protocol, are significantly correlated to bone strength. Such a correlation would identify BMD measurements, collected my means suited to longitudinal and screening studies, and a useful indicator of bone strength. This study aimed to establish if this correlation exists.

\section{MATERIALS AND METHODS}

\section{Animals and Specimens}

Animals used to provide material for this study were normal commercial production pigs, and the material 
Table 1. Distribution of different herd factors for the pigs included in this study

\begin{tabular}{lc}
\hline \hline Factor & Percentage \\
\hline Purebred & 12 \\
Crossbred & 88 \\
Box or tethers during gestation & 35 \\
Group-housed during gestation & 60 \\
Both of the above during gestation & 5 \\
Principle of feeding & \\
Random & 64 \\
Secured & 36 \\
Feed & \\
Purchased, dry & 25 \\
Purchased, liquid & 5 \\
Home-grown, dry & 53 \\
Home-grown, liquid & 14 \\
Combinations of the above & 3 \\
Dry (in total) & 80 \\
Liquid (in total) & 20 \\
Solid, during gestation & 12 \\
Slatted, during gestation & 88 \\
\hline
\end{tabular}

was collected after normal slaughter. There were no animal care and use committee concerns.

In an earlier study, the right and left metacarpal bones from 698 pigs, collected at 3 geographically separate slaughter facilities in Denmark, were classified into 3 groups by BMD determined by DXA. Herd factors for these animals are given in Table 1. The DXA measurements taken from these animals were taken from the metacarpal and phalangeal bones. The samples were considered representative of production pigs from commercial farms. The groups were as follows: BMD $<1 \mathrm{~g} / \mathrm{cm}^{2}$ (low), BMD 1 to $1.4 \mathrm{~g} / \mathrm{cm}^{2}$ (medium), and BMD $>1.4 \mathrm{~g} / \mathrm{cm}^{2}$ (high). Sample size (30 pairs per group) was determined after considering statistical and economic factors. Pairs were selected randomly and kept in storage at $-18^{\circ} \mathrm{C}$ until use. From the samples, paired (right and left), fourth metacarpal bones were dissected free from the remaining tissue. In some cases, separation of the fourth from the third metacarpal bone was not possible so that 30,28 , and 26 pairs from the low, medium, and high BMD groups, respectively, were available for further testing. Thus, 168 individual bones were tested. After dissection, the overlying soft tissue was removed by hand, the bones were wrapped in gauze, which was then moistened with $0.9 \%$ saline, and then returned to storage at $-18^{\circ} \mathrm{C}$.

\section{Morphological Measurements}

The specimens were imaged with computed tomography (Somatom Plus 4, Siemens, Forchheim, Germany) using a sequential scanning mode. Collimation was set at 5-mm slice thickness, and images were obtained at $120 \mathrm{kV}$ and $200 \mathrm{~mA}$. An imaging window suitable for bone (100 and 3,071 HU) was used, and the volume of bone present was calculated from the entire image sequence. Cortical thickness was read from a single slice, obtained at the middiaphysis (the site of the com-

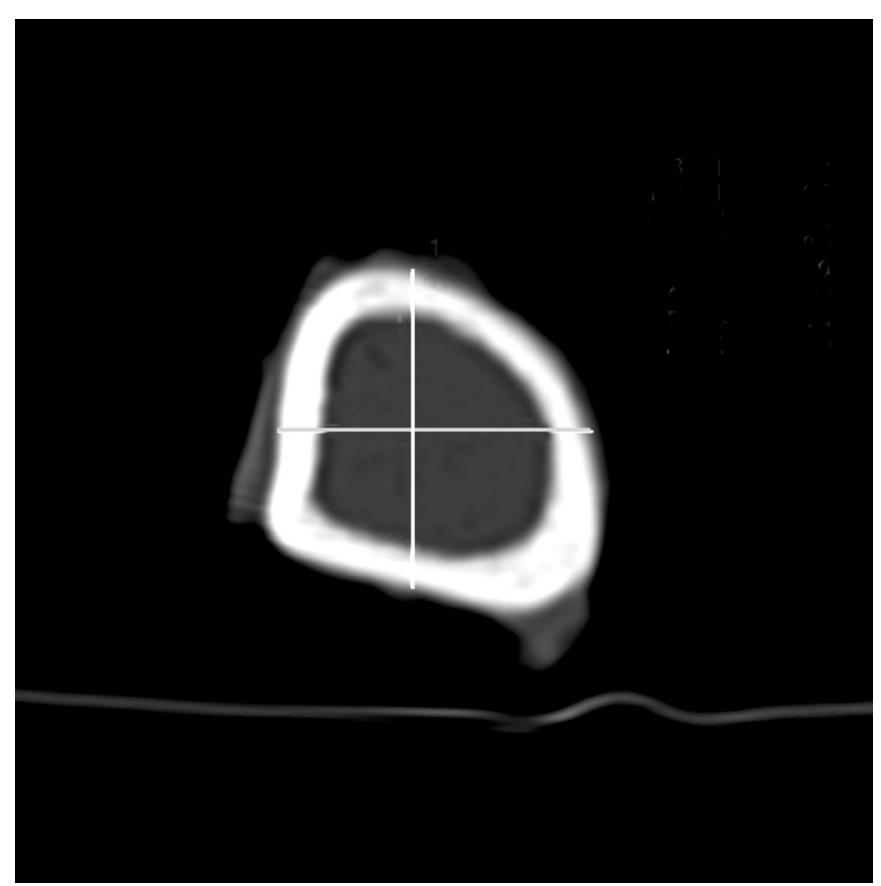

Figure 1. Computed tomographic image of the middiaphysis of the fourth metacarpal bone. The orthogonal lines show the locations at which the distance measurements were made. The length of the external and internal diameters of the bone was determined in 2 planes at right angles to each other.

pression test; see below), together with the internal and external diameters of the bone in the direction of and orthogonal to the compression axis (Figure 1). Bone length was determined from the image sequence. In all images analyzed, the bone edges were identified, based on Hounsfield units, and the measurements were reported directly or were used in the calculation of the bone strength variables. After imaging, the samples were returned to storage at $-18^{\circ} \mathrm{C}$.

\section{3-Point Bending Test}

Before the 3-point bending test, samples were thawed in saline at room temperature $\left(23^{\circ} \mathrm{C}\right)$ for $24 \mathrm{~h}$. This test was made on all of the bone samples using a dedicated apparatus (Lloyd Instruments LR50 K, Ametek Inc., Fareham, UK) running the Lloyd Instruments 1996 Addendum Version 1 (Addition to Windows R Control V1.10) equipped with a $5-\mathrm{kN}$ load cell. After calibration, each sample was placed between the 3 loading points on the unit, the center point positioned at the middiaphysis, and the 2 remaining points at the opposite side of the bone and toward each bone extremity. The distance between the bars at the extremities was kept constant for all samples at $27.32 \mathrm{~mm}$ (Figure 2). The rate of loading was $15 \mathrm{~mm} / \mathrm{min}$ until the maximum (breaking point).

For each specimen, the unit yielded a plot of the deformation produced over the range of loads applied, 


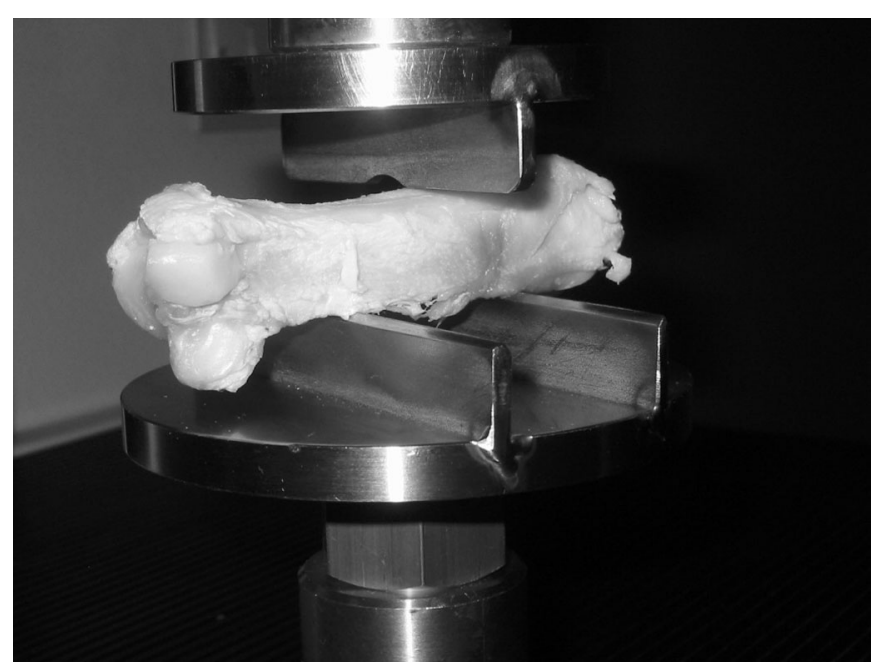

Figure 2. Three-point bending apparatus. A fourth metacarpal bone is supported on its lower side at 2 points, and compression is applied at a single point from above.

i.e., a load deformation curve (Figure 3). From this curve, the maximum load ( $\mathrm{N}$; load at breaking point) and stiffness $(\mathrm{N} / \mathrm{mm}$; the slope of the load deformation curve) can be read. The area over which the load is applied is determined from the computed tomographic measurements and so a value for stress can be calculated. Stress at maximum load $\left(\mathrm{N} / \mathrm{m}^{2}\right.$; the force per unit area at breaking) and the elastic modulus (slope of the stress strain curve for the preparation) were calculated.

\section{Ash and Mineral Determination}

The percentage of $\mathrm{P}$ and $\mathrm{Ca}$ contents were determined by a commercial laboratory (AnalyCen A/S, Fredericia, Denmark) in all of the bones included in this study according to their in-house protocol. This involved manual removal of soft tissues, determination of the dry weight, grinding to a fine powder, and removal of fat using an organic solvent. The fat-free powder was weighed and then ashed at $550^{\circ} \mathrm{C}$ for $6 \mathrm{~h}$. The weight of the material remaining, i.e., ash, was determined and compared with the weight of the original fat-free bone powder sample. Mineral assay was determined by optical emission spectrum photometry.

\section{Statistical Analyses}

The data were analyzed using PROC GLM (SAS Inst. Inc, Cary, NC). The low, medium, and high BMD groups were used as class variables. A linear model for 1-way ANOVA was used, as follows: $\mathrm{Yij}=\mu+\alpha_{\mathrm{i}}+\mathrm{e}_{\mathrm{ij}}$, where $\mathrm{i}=$ the class variables and $\mathrm{j}=$ the number of replicates in each group. Multiple-range testing was done by use of the Bonferroni's test for each variable.

\section{RESULTS AND DISCUSSION}

The selection procedure resulted in 84 paired samples in all. All samples were collected from production sows

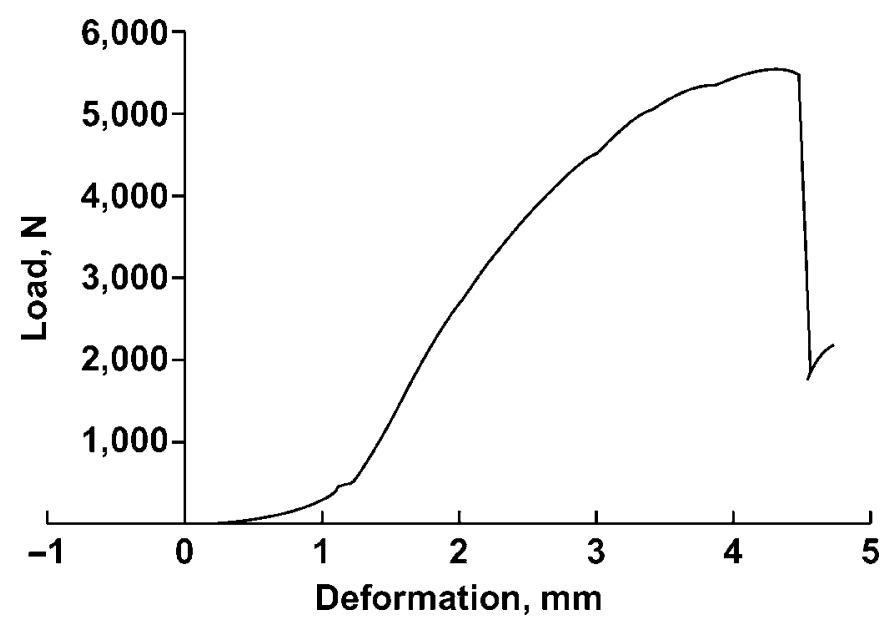

Figure 3. Load deformation curve for 1 individual. Load in Newtons is plotted against deformation in millimeters. The slope of the straight-line region relates to stiffness. Maximum load occurs at the breaking point (seen on the graph as the sudden drop in load) in this specimen.

in commercial herds and are thus typical of material encountered in normal pig production in Denmark (Table 1). The DXA scan and the bone strength test used in this study were performed on postmortem specimens. The treatment and storage of the samples was such that no significant postmortem alteration of the variables measured would have occurred for either category of test (Turner and Burr, 1993). The samples were identified in previous studies as being readily available at low cost and yielded reproducible results on DXA scanning. The BMD data from the population used in this study has previously been shown to correlate with aspects of husbandry including floor type and freedom of movement (free range or confined; Nielsen et al., 2004; Madsen et al., 2005). In clinical and experimental settings, DXA continues to be a useful tool for bone and body composition measurements. This is especially so in the light of recent improvements in the technique, which is now accepted as being simple to perform, reproducible, and widely available (Albanese et al., 2003). Although DXA is still considered the gold standard for BMD measurements (Lewiecki, 2005), peripheral quantitative computed tomography has also been used to determine BMD. This latter technique yields a volumetric result for BMD $\left[\mathrm{g} / \mathrm{m}^{3}\right.$, which can be combined with indices of bone geometry (e.g., cortical cross-sectional area) to yield the bone strength index]. This approach is attractive because it integrates the contributions of geometry and material to bone strength. Recent reports, however, conclude that areal BMD $\left[\mathrm{g} / \mathrm{m}^{2}\right.$ derived from bone mineral concentration] over the projected area, which is also an integration of the contributions of geometry and material, may have similar value to the bone strength index for predicting bone strength 
Table 2. Comparison by bone mineral density (BMD) group of metacarpal bone measurements determined from computed tomography scans ${ }^{1}$

\begin{tabular}{|c|c|c|c|c|c|c|c|c|c|}
\hline $\begin{array}{l}\text { BMD } \\
\text { group }\end{array}$ & $\begin{array}{l}\text { Group } \\
\text { size }\end{array}$ & $\begin{array}{c}\text { Cortical } \\
\text { thickness, } \\
\text { mm }\end{array}$ & SEM & $\begin{array}{l}\text { Length, } \\
\mathrm{mm}\end{array}$ & SEM & $\begin{array}{l}\text { Volume, } \\
\mathrm{mm}^{3}\end{array}$ & SEM & $\begin{array}{c}\text { Volume/unit } \\
\text { length, } \\
\mathrm{mm}^{3} / \mathrm{mm}\end{array}$ & SEM \\
\hline Low & 30 & 0.9 & 0.02 & 8.2 & 0.12 & 19.9 & 0.60 & 2.4 & 0.06 \\
\hline Medium & 28 & 1.2 & 0.02 & 8.8 & 0.11 & 24.8 & 0.62 & 2.8 & 0.06 \\
\hline High & 26 & 1.3 & 0.02 & 9.0 & 0.12 & 29.8 & 0.65 & 3.3 & 0.06 \\
\hline
\end{tabular}

${ }^{1}$ Values given are means together with the SEM.

${ }^{2}$ Cortical thickness is the sum of cortical bone thicknesses in the direction of and orthogonal to the axis of compression.

(Siu et al., 2003). Areal BMD and not volumetric BMD was used to provide the data in this study.

There was no significant difference between right and left limbs for any of the variables reported, so data from the right and left in each individual for each variable were combined, and the average was used. The mean $\mathrm{BMD}$ of the selected specimens within each of the 3 BMD groupings was $0.8921,1.2971$, and $1.5315 \mathrm{~g} / \mathrm{cm}^{2}$ (low, middle, and high, respectively). A computed tomography image from the middiaphysis at the site of compression is shown in Figure 1. The cortical bone thickness at the compression site and the bone length and volume in each of the BMD groups show that the physical dimension of the bones relate to BMD grouping (Table 2). Bones with greater BMD have larger dimensions. Techniques to measure bone strength are reported in the literature. The 3-point bending test used in this study is widely reported (Turner and Burr, 1993; Stromsoe et al., 1995). This test yields a curve showing the relationship between the load or stress applied to bone and the deformation or strain that results. From this curve, many variables can be extracted. The 3point bending test of a bone specimen is illustrated in Figure 2, and a typical load deformation curve for an individual is shown in Figure 3. Values of maximum load, stiffness, stress at maximum load, and elastic modulus are given in Table 3 for each of the BMD groups. The values for stress at maximum load in Table 3 show a significant difference among groups, i.e., bones are not only getting progressively larger from the low
BMD group to the high group, but they also have greater intrinsic (material) strength. The results give an indication of the mechanical properties of the bone examined and the risk of fracture. Fracture risk must also be related to the type of stimulus, such as the repeated bone loading of the type associated with fatigue fractures or the excessive loading that results in fracture after a single load application. In stating fracture risk, the physical nature of the load applied to bone as well as the mechanical properties of the bone must be considered (Turner and Burr, 1993). The quantification of bone strength is a complex biomechanical issue. One can consider the inherent strength of the material making up the bone and also, separately, the strength of the assembled complete bone. The analogy of the distinction between the strength of a building material to that of the final completed building has been made (Turner and Burr, 1993). In our study, the variable elastic modulus was reported, and this is accepted as a property of the material itself (Currey, 2001). Elastic modulus is derived from the slope of a stress strain curve of the object under test. Likewise, stress at maximum load, the force per unit area on the bone at the maximum possible applied force (typically, at breaking point for bone), is an intrinsic property of the material, independent of size and shape of the bone. Stiffness is a property of the entire bone. It is sometimes called extrinsic stiffness and is measured from the load deformation curve of the bone under test. The quantity, maximum load, is also a property of the entire bone

Table 3. Comparison by bone mineral density (BMD) group of maximum load, stiffness, stress at maximum load, and elastic modulus determined from the 3 -point bending test, showing significant statistical differences ${ }^{1}$

\begin{tabular}{|c|c|c|c|c|c|c|c|c|c|c|c|}
\hline $\begin{array}{l}\text { BMD } \\
\text { group }\end{array}$ & $\begin{array}{l}\text { Group } \\
\text { size }\end{array}$ & $\begin{array}{l}\mathrm{BMD}, \\
\mathrm{g} / \mathrm{cm}^{2}\end{array}$ & SEM & $\begin{array}{l}\text { Maximum } \\
\text { load, N }\end{array}$ & SEM & $\begin{array}{c}\text { Stiffness, } \\
\text { N/mm }\end{array}$ & SEM & $\begin{array}{l}\text { Stress at } \\
\text { maximum } \\
\text { load, } \\
\mathrm{N} / \mathrm{mm}^{2}\end{array}$ & SEM & $\begin{array}{c}\text { Elastic } \\
\text { modulus, } \\
\mathrm{N} / \mathrm{mm}^{2}\end{array}$ & SEM \\
\hline Low & 30 & 0.8921 & 0.0076 & $2,536^{\mathrm{a}}$ & 129 & $904^{\mathrm{a}}$ & 114 & $386^{\mathrm{a}}$ & 22 & $765^{\mathrm{a}}$ & 73 \\
\hline Middle & 28 & 1.2971 & 0.0079 & $5,400^{\mathrm{b}}$ & 134 & $2,414^{\mathrm{b}}$ & 118 & $573^{\mathrm{b}}$ & 23 & $1,222^{\mathrm{b}}$ & 76 \\
\hline High & 28 & 1.5315 & 0.0081 & $7,032^{\mathrm{c}}$ & 139 & $3,371^{\mathrm{c}}$ & 122 & $707^{\mathrm{c}}$ & 24 & $1,433^{\mathrm{b}}$ & 78 \\
\hline
\end{tabular}

${ }^{\mathrm{a}-\mathrm{c}}$ Within a column, means without a common superscript letter differ $(P<0.001)$.

${ }^{1}$ Maximum load and stiffness (slope of the load deformation curve in its linear region defined by visual inspection) was read directly from the curve. Stress at maximum load and elastic modulus were calculated. Values given are means together with the SEM. 
Table 4. Comparison by bone mineral density (BMD) group of ash and mineral content of the fourth metacarpal bones ${ }^{1}$

\begin{tabular}{lccccccccc}
\hline \hline $\begin{array}{l}\text { BMD } \\
\text { group }\end{array}$ & $\begin{array}{c}\text { Group } \\
\text { size }\end{array}$ & $\begin{array}{c}\text { BMD, } \\
\text { g/cm }{ }^{2}\end{array}$ & SEM & $\begin{array}{c}\text { Ash, } \\
\%\end{array}$ & SEM & $\begin{array}{c}\text { Ca, } \\
\text { g/kg }\end{array}$ & SEM & $\begin{array}{c}\text { P, } \\
\text { g/kg }\end{array}$ & SEM \\
\hline Low & 30 & 0.8921 & 0.0076 & $57.5^{\mathrm{a}}$ & 0.44 & $184^{\mathrm{a}}$ & 3.5 & $88^{\mathrm{a}}$ & 1.6 \\
Middle & 28 & 1.2971 & 0.0079 & $61.3^{\mathrm{b}}$ & 0.45 & $195^{\mathrm{b}}$ & 3.6 & $92^{\mathrm{ab}}$ & 1.7 \\
High & 28 & 1.5315 & 0.0082 & $62.6^{\mathrm{b}}$ & 0.47 & $208^{\mathrm{b}}$ & 3.8 & $97^{\mathrm{b}}$ & 1.8 \\
\hline
\end{tabular}

${ }^{\mathrm{a}, \mathrm{b}}$ Within a column, means without a common superscript letter $\operatorname{differ}(P<0.001)$.

${ }^{1}$ Values given are means together with the SEM.

and is read directly from the load deformation curve at the point where the bone accepts maximum loading. This will typically be at the breaking point for bone, but maximum load and load at breaking point can be different in some materials. Both elastic modulus and stress at maximum load are measures of material strength and are reported in Table 3. Elastic modulus, however, does not show the same increase with increasing BMD as stress at maximum load.

Alteration in size is proposed as the primary means of adaptation to increased loading. This proposal is based on findings that larger bones have similar cortical $\mathrm{BMD}$, i.e., volumetric BMD, compared with smaller bones (Haapasalo et al., 2000). Our results for the low to middle BMD group in Tables 2 and 3 show that an increase in entire bone strength (indicated by maximum load and stiffness and a function of increased loading) is related not only to size but also to material strength (as measured by stress at maximum load and elastic modulus).

Values of ash percentage and $\mathrm{P}$ and $\mathrm{Ca}$ content for each of the BMD groups are shown in Table 4. These data do not give a clear trend. Although there is a difference, for example, between low and middle BMD groups for ash percentage, this difference is not seen between bones in the middle and high groups. The projected changes in value of ash, $\mathrm{P}$ and $\mathrm{Ca}$, maximum load, stress, stiffness, and elastic modulus per unit change in BMD are given in Table 5. There are significant associations between BMD and all variables measured. The $R^{2}$ value associated with some of the variables is high, indicating that the linear model adequately describes the relationship of that variable with BMD. For other variables, however, although there is a significant association with BMD, the $\mathrm{R}^{2}$ is low and thus the linear model used does not adequately describe the relationship.

The results show that a correlation exists, in the material used for this study, between BMD and bone strength. With respect to bone strength, BMD correlated with variables relating to both the intrinsic (or material) strength and extrinsic (relating to structural) strength of the bone.

Given the linkage shown in this study between BMD and bone strength, it can be accepted that the risk of fracture in the tissue examined relates to BMD. However, the use of BMD measured at 1 site to estimate fracture risk at another site in the same animal is problematic. It is reasonable to suggest that animals with lower BMD are in general at greater risk of fracture than animals with greater BMD. This cannot be tested using the data obtained in this study. In humans, BMD data obtained from specific sites have been widely used when making general predictions concerning fracture risk throughout the skeleton (Faulkner, 2000).

If specific sites appear prone to fracture in a population, then BMD measurements from these specific sites rather than the site used for the data in this study would be appropriate and would likely be the best predictor of fracture at that site. However predilection fracture sites, if they exist, have not been identified in commercial production pigs.

The strong correlation between BMD and both intrinsic and extrinsic variables of bone strength demonstrated in this study indicates that DXA results obtained in a manner such as that used for this study

Table 5. Relationship between unit alteration in bone mineral density (BMD) and bone composition and bone strength in the fourth metacarpal bone ${ }^{1}$

\begin{tabular}{lccccccc}
\hline \hline & & \multicolumn{9}{c}{$\begin{array}{c}\text { Stress at } \\
\text { maximum } \\
\text { load, }\end{array}$} & $\begin{array}{c}\text { Stiffness, } \\
\mathrm{N} / \mathrm{mm}\end{array}$ & $\begin{array}{c}\text { Elastic } \\
\text { modulus, } \\
\mathrm{N} / \mathrm{mm}^{2}\end{array}$ \\
& $\begin{array}{c}\text { Ash, } \\
\text { Item }\end{array}$ & $\begin{array}{c}\mathrm{P}, \\
\mathrm{g} / \mathrm{kg}\end{array}$ & $\begin{array}{c}\mathrm{Ca}, \\
\mathrm{g} / \mathrm{kg}\end{array}$ & $\begin{array}{c}\text { Maximum } \\
\text { load, } \mathrm{N}\end{array}$ & $\mathrm{N} / \mathrm{mm}^{2}$ & \\
\hline Change in BMD & & & & & & \\
$\left(0.1 \mathrm{~g} / \mathrm{cm}^{2}\right)$ & $0.84^{* * *}$ & $1.4^{* * *}$ & $3.5^{* * *}$ & $708^{* * *}$ & $50^{* *}$ & $391.6^{* *}$ & $108^{* *}$ \\
$\mathrm{R}^{2}$ & 0.48 & 0.16 & 0.20 & 0.91 & 0.58 & 0.78 & 0.36 \\
\hline
\end{tabular}

\footnotetext{
${ }^{1}$ Based on the linear regression equation $\mathrm{Y}_{\mathrm{i}}=\alpha+\beta\left(\mathrm{BMD}_{\mathrm{i}}\right)+\mathrm{e}_{\mathrm{i}}$, where $\beta=$ the slope. Probability values indicate the probability that $\beta \neq 0$.

$* * P<0.001 ; * * * P<0.0001$.
} 
should be taken as one factor in fracture risk assessment protocols in adult production pigs.

\section{LITERATURE CITED}

Albanese, C. V., E. Diessel, and H. K. Genant. 2003. Clinical applications of body composition measurements using DXA. J. Clin. Densitom. 6:75-85.

Alho, A., T. Husby, and A. Hoiseth. 1988. Bone mineral content and mechanical strength. An ex vivo study on human femora at autopsy. Clin. Orthop. Relat. Res. 227:292-297.

Christensen, G., and H. Wachman. 2001. Knoglebrud hos slagtede søer. Landsudvalget for Svin. Meddelelse no. 522. Info Svin, Denmark.

Currey, J. D. 2001. Bone strength: What are we trying to measure? Calcif. Tissue Int. 68:205-210.

Faulkner, K. G. 2000. Bone matters: Are density increases necessary to reduce fracture risk? J. Bone Miner. Res. 15:183-187.

Haapasalo, H., S. Kontulainen, H. Sievanen, P. Kannus, M. Järvinen, and I. Vuori. 2000. Exercise-induced bone gain is due to enlargement in bone size without a change in volumetric bone density: A peripheral quantitative computed tomography study of the upper arms of male tennis players. Bone 27:351-357.

Iida-Klein, A., C. Hughes, S. S. Lu, A. Moreno, V. Shen, D. W. Dempster, F. Cosman, and R. Lindsay. 2006. Effects of cyclic versus daily hPTH (1-34) regimens on bone strength in association with BMD, biochemical markers, and bone structure in mice. J. Bone Miner. Res. 2:274-282.

Koo, M. W., K. H. Yang, P. Begeman, M. Hammami, and W. W. Koo. 2001. Prediction of bone strength in growing animals using noninvasive bone mass measurements. Calcif. Tissue Int. 68:230-234.

Lewiecki, E. M. 2005. Clinical applications of bone density testing for osteoporosis. Minerva Med. 96:317-330.

Madsen, M. T., D. H. Nielsen, F. J. McEvoy, and E. Svalastoga. 2005. Correlation between herd factors and bone strength, expressed by DEXA, in Danish sows. Dan. Vet. 87:21-29.

Nielsen, D. H., F. J. McEvoy, H. L. Poulsen, M. T. Madsen, L. E. Buelund, and E. Svalastoga. 2004. Dual-energy X-ray absorptiometry of the pig: Protocol development and evaluation. Meat Sci. 68:235-241.

Siu, W. S., L. Qin, and K. S. Leung. 2003. pQCT bone strength index may serve as a better predictor than bone mineral density for long bone breaking strength. J. Bone Miner. Res. 21:316-322.

Stenstrom, M., B. Olander, D. Lehto-Axtelius, J. E. Madsen, L. Nordsletten, and G. A. Carlsson. 2000. Bone mineral density and bone structure variables as predictors of bone strength: An analysis using computerized microtomography and gastrectomy-induced osteopenia in the rat. J. Biomech. 33:289-297.

Stromsoe, K., A. Hoiseth, A. Alho, and W. L. Kok. 1995. Bending strength of the femur in relation to non-invasive bone mineral assessment. J. Biomech. 28:857-861.

Turner, C. H., and D. B. Burr. 1993. Basic biomechanical measurements of bone: A tutorial. Bone 14:595-608.

Van der Meulen, M. C., K. J. Jepsen, and B. Mikic. 2001. Understanding bone strength: Size isn't everything. Bone 29:101-104.

Wachter, N. J., G. D. Krischak, M. Mentzel, M. R. Sarkar, T. Ebinger, L. Kinzl, L. Claes, and P. Augat. 2002. Correlation of bone mineral density with strength and microstructural variables of cortical bone in vitro. Bone 31:90-95. 